\title{
ARTICLE
}

\section{Ethical perspectives on suicide and suicide prevention}

\author{
Chris Kelly \& Eric Dale
}

\begin{abstract}
Chris Kelly has worked as
a consultant in general adult psychiatry in South Yorkshire for the past 22 years. Eric Dale is an ST5 trainee on the North Trent general adult rotation currently working in Doncaster. He is studying for an MA in Healthcare Ethics at the University of Leeds. Correspondence Dr Eric Dale, Rotherham, Doncaster and South Humber Mental Health NHS Foundation Trust, St Catherine's, Tickhill Road, Doncaster DN4 80N, UK. Email: Eric.Dale@rdash.nhs.uk
\end{abstract}

\begin{abstract}
SUMMARY
Philosophy both influences and is influenced by clinical and legal practice relating to suicide. This article begins with a brief history of attitudes in the UK and Europe towards those who attempt suicide. It describes the main philosophical positions regarding suicide, including the principle of respect for life, the utilitarian position, the theological principle, and the principles of autonomy and duty to others. It concludes that short-term interventions are justified in most cases, for example when the suicide attempt is a 'cry for help' and/or the individual is ambivalent in their attempt or likely to have a mental illness.

\section{DECLARATION OF INTEREST}

None.
\end{abstract}

Suicide has long been a concern of moral philosophers and theologians. Their thinking has influenced both popular opinion and medico-legal practice regarding suicide and suicide prevention. Albert Camus (1913-1960) claimed that 'there is but one serious philosophical problem, and that is suicide. Judging whether life is or is not worth living amounts to answering the fundamental question of philosophy' (Camus 1942).

Christian theology has influenced attitudes and practices regarding suicide in the UK and Europe for many centuries. Influential thinkers such as St Augustine of Hippo (354-430 AD) and St Thomas Aquinas (1225-1274 AD) held that suicide is wrong because it involves an offence against God: life is given by God, and taking one's own life therefore breaks the biblical commandments against stealing and murder (Biggar 2004). A 'suicide mania' among Christian martyrs prompted St Augustine to publicly condemn the act (Alvarez 1980). Immanuel Kant (1724-1804) propounded these views and the belief that humans are sentinels who must not desert their posts unless given a divine command to do so (Battin 1996: p. 33). However, the philosopher David Hume's (1711-1776) position on suicide includes the view that suicide is not only permissible for the individual but in some cases for their family and society as a whole (Hume c. 1755).

Suicide was once illegal in Britain. Suicide attempts were punishable by public execution and there are accounts of such executions as late as 1860 . People who died by suicide, and those executed for their attempts, were buried at crossroads in the belief that their spirit would not be able to find their way back to their towns (Alvarez 1980: p. 8). Suicide was decriminalised in 1961 in England and Wales with the Suicide Act. It was decriminalised in Scotland in the same year by this Act, and in Northern Ireland in 1966, when sections 1 and 2 of the Act were enacted by sections 12 and 13 of the Criminal Justice Act (Northern Ireland) 1966. Considering that there should be ethical limits on the permissibility of suicide does not equate with a view that people who attempt suicide are somehow in the wrong. Clearly this would serve only to worsen their situation and the views of society towards those who attempt suicide and, by extension, people with certain mental illnesses.

\section{Suicide and the media}

Suicide remains a contentious issue. The National Union of Journalists in Scotland published guidelines in 2007 on acceptable reporting of suicide (NUJ Scotland 2007). Their advice includes avoiding printing details of drugs and dosages used in suicide attempts. Using sensitive terminology is recommended, as is avoiding describing a completed suicide as 'successful'.

There is clear evidence that media portrayals of suicide influence the public, irresponsible reporting increasing imitation (Schmidtke 1989). Pirkis (2009) writes about the 'Werther effect', where an increased rate of suicide - both attempted and completed - follows a media depiction of a person's death by suicide. Such an increase followed the suicide of Kurt Cobain, for example (Jobes 1996). The effect has been shown to apply to both fictional stories and non-fictional media reports (Stack 1991; Hawton 1999).

\section{Rational and irrational suicide}

Concerns regarding the rationality of suicide involve a weighing up of the positive and negative results of a proposed act of suicide and coming to a conclusion as to whether the act is of overall benefit or not. The effect of the suicide on others (such as financial hardship resulting from it) will be a crucial part of 
this assessment. Brandt (1980) and Glover (1990) consider factors relating to the suicidal individual and effects on others, for example the family of the suicide victim. Individual factors include the distorting influence of acute distress and depression on cognition, making the future appear bleaker than is in fact likely. Brandt classifies suicides based on acute distress or depression as irrational, implying that they are morally impermissible (Brandt 1980). His opinion is that there is a good chance that the future in such cases will improve; therefore the person will be losing out on positive value by ending their life prematurely.

One justification which is held to permit suicide is terminal illness. The thinking behind this is that the negative value in the person continuing to live in pain with loss of dignity outweighs other considerations counting against their suicide (Brandt 1980; Beauchamp 1993). However, many would disagree with this view on the grounds that life's intrinsic value is not dependent on individual suffering. Some ethicists hold that it is not justifiable to prevent the suicide of rational individuals seeking death for reasons such as these (Brandt 1980).

\section{Philosophical positions on suicide}

The philosopher Tom Beauchamp (1993) divides factors in the ethical analysis of suicide into five categories: those involving the principle of respect for life, the theological position, the principle of autonomy, the principle of duty to others and the utilitarian position.

\section{Respect for life and the theological position}

The principle of respect for human life posits that life has an intrinsic value that is deserving of respect (Beauchamp 1993: p. 85). Suicide is viewed as impermissible as it amounts to the intentional taking of a fundamental good - life itself. However, Baelz (1980) raises the point that in some situations, for example in self-defence, killing is widely accepted as morally permissible. By extension, suicide may be a permissible exception to the principle of respect for life in some cases, for example if an individual is terminally ill and is certain to die a prolonged death in great pain.

It could be argued that the National Suicide Prevention Strategy for England describes the rationale for a suicide prevention strategy in terms of the principle of respect for life, stating that 'each suicide represents both an individual tragedy and a loss to society' (Department of Health 2002: p. 8).

The theological position relates to the principle of respect for life: for Christians, God is viewed as creator and so taking one's life is disrespectful towards God (Baelz 1980).

\section{Suicide and autonomy}

Beauchamp (1993: p. 84) describes the principle of autonomy as asserting 'an obligation to respect the decision making capacities of autonomous persons by not limiting their liberty to effect their choices'. His definition of the capacity to make autonomous decisions is similar to the current definition of the legal concept of mental capacity. ${ }^{\dagger}$ Such capacity, he writes, requires the 'ability to grasp, appreciate the significance of, form relevant intentions and not be controlled by either internal or external forces that the person cannot resist'. Mental capacity and the principle of autonomy can thus be seen to be closely related.

The moral permissibility of suicide raised by the principle of autonomy does not apply to individuals who are unable to make autonomous decisions. It is considered to be morally impermissible to allow an individual without decision-making capacity to take their own life. If the lack of capacity is temporary, the person might decide against suicide when capacity is regained.

In his influential essay Of Suicide (Hume c. 1755), David Hume defended a position first put forward by classical Greek scholars that suicide is an honourable act. Humes' argument is based on an appeal to autonomy and utility. In a discussion of a number of situations in which suicide might be considered, Hume concludes that in some cases it would be in the interests of the individual, their family and society. One example is the case of a spy who is captured and kills himself to avoid divulging state secrets. Hume argues that if the spy did not kill himself he would be unhappy for the rest of his life.

Emile Durkheim (1858-1917) says of altruistic suicide: 'The weight of society is ... brought to bear [on the individual] to lead him to destroy himself' (Durkheim 1897; 2005 reprint: p. 178). This form of suicide is expected and condoned by society and 'the sacrifice is imposed for social ends' (p. 178). The suicide by self-immolation of Jan Palach in the former communist Czechoslovakia during the 1968 'Prague Spring' protests could be argued to be an example of this (O'Connor 2009).

\section{Duty to others}

Battin (1996) identifies duty to others as a further argument in favour of suicide prevention. In her view, if an individual makes a rational choice to end their life and there is no impairment in that person's autonomy, then paternalistic intervention is generally morally forbidden. However, in specific cases, a duty to others would make intervention permissible (p. 143). For example, a man intends to take his own life as he has a painful terminal illness, but his wife has strong religious beliefs against

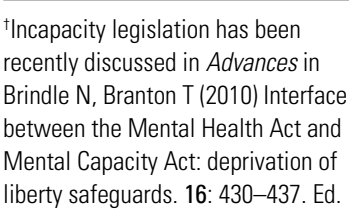

Incapacity legislation has been ecently discussed in Advances in between the Mental Health Act and liberty safeguards. $16: 4$ 
suicide. In such a situation, short-term intervention would be justified to assess the man for mental illness and ambivalence, and to provide treatment and counselling where appropriate.

If, after a short period of paternalistic intervention (see below), a rational, autonomous individual still intends suicide, it is generally considered wrong to stop them from killing themselves (Beauchamp 1993; Cosculluela 1995). Again, however, there are possible exceptions. Such a situation is illustrated in the fictitious example in Box 1. This shows that short-term paternalistic intervention for a second time may be justified with a rational, autonomous individual, even though there is no duty to others or known ambivalence or mental illness, but where it is possible that the person's state of mind has changed.

\section{The utilitarian position}

John Stuart Mill, one of the most influential utilitarian philosophers of the 19th century, asserted that suicide prevention is never justified after an initial attempt has been made to find the cause. Mill states that we 'are justified in temporarily intervening in order to ensure that a person is acting intentionally with adequate knowledge of the consequences of the action', but that once this has been done the person should be allowed to do as they please (Mill 1859). Beauchamp (1993) explains that Mill viewed any form of exercising power over a person, other than to prevent harm to others, as wrong. Although Mill would allow remonstration with the person or an attempt to persuade them not to kill themselves, he believed that '[an individual's] independence is, of right, absolute'.

Independence and personal freedom are clearly important rights that society must aim to preserve. It is unclear, however, whether by 'temporarily

BOX 1 Suicide attempt by a person recently assessed as having no mental illness

A rational, autonomous person with no family, debts or dependants finds that he has a terminal illness. He voices suicidal thoughts and is assessed by the local crisis intervention team: they find no evidence of mental illness. A few months later he tries to jump out of an office window to his death. It would be permissible, most would say obligatory, for the people in the room to restrain him. They do not know his full history and are therefore acting in good faith to save his life. It could then be argued that it is morally obligatory for a second mental health assessment to be carried out: the fact that the attempt was made in the presence of others may indicate a certain degree of ambivalence and also there may have been a change in his mental state since the first assessment. intervening' Mill would sanction intervention limited to hours, to a few words with a person about to jump from a bridge, or to detention under the Mental Health Act with police assistance and an assessment and support over a number of days, even weeks if necessary.

It is worth considering that in Mill's lifetime there were no effective treatments for mental illness, which is now known to be a factor in many suicides (Appelby 2001). Also his position does not allow the possibility that an individual about to kill themselves is ambivalent about their death.

\section{Perspectives on suicide prevention}

\section{Public and professional obligations}

The principle of respect for life suggests that members of the public are morally justified and possibly obligated to report suicide threats. This view can be extrapolated to include a moral obligation to prevent suicide. In some cases this would involve coercion, because if a member of the public is obligated to report a suicide threat then it would be unreasonable not to expect authorities such as the police and mental health services to share that obligation with a view to stopping a person from killing themselves.

As mentioned above, the evidence that in the majority of cases of completed suicide the individual had a mental illness provides further moral justification for suicide prevention measures. Barraclough (1974) conducted one of the first studies to demonstrate this high prevalence of psychiatric illness, showing that in 93 of the 100 suicides studied the individuals had a diagnosed mental disorder: 70\% had depression and 15\% had alcohol dependence. Similar findings were reported more than 25 years later, in data from the 19962001 National Confidential Inquiry into Suicide and Homicide by People with Mental Illness (Appelby 2001). Depression was the single most common diagnosis in people who had died by suicide and had been in contact with mental health services in the year before death.

It is reasonable to assume that not all depressed, suicidal patients lack the capacity to make autonomous decisions, given the spectrum of severity of depression and the fact that most patients with depression are mildly depressed. However, allowing acutely suicidal autonomous individuals with depression to kill themselves would deprive them of the opportunity of treatment that is likely to render them no longer suicidal.

We cannot know how many people who take their own lives had an undiagnosed mental illness. However, it is reasonable to assume that a significant proportion who were not in contact with 
mental health services will have had mental health problems, given the roughly $20 \%$ lifetime prevalence of depression in the general population (Kessler 1994). Also, a systematic review revealed that approximately $90 \%$ of individuals who completed suicide were found in psychological autopsy studies to have had a mental illness (Cavanagh 1993).

\section{The 'cry for help' and ambivalence}

It has been suggested that for some, a suicide attempt is the person's high-risk strategy for altering their situation - a 'cry for help' (Battin 1996). The intention is not death but another end, perhaps attention, reconciliation or revenge. The cry for help model incorporates elements of the view that many suicide attempts involve ambivalence: the parts of the patient's psyche that want to live and the parts that wish to die may be present in different proportions at different times (Battin 1996).

\section{Paternalism and suicide prevention}

The high prevalence of mental illness among people who attempt (and complete) suicide, the possibility that death is not the purpose of a suicide attempt and that the person may feel ambivalent about death provide moral justification for paternalistic shortterm suicide prevention measures in autonomous, capacitous individuals.

Paternalistic interventions to prevent suicide have been discussed at length in the literature (Beauchamp 1993; Cosculluela 1995; Battin 1996). Dworkin (1972) describes paternalism as 'the abridgement of an individual's liberty or other rights in order to promote his or her interests, good, happiness, needs, values or welfare'. Beauchamp (1993) concludes that paternalism applies only to autonomous individuals. If an individual lacks autonomy, i.e. is incapable of making capacitous decisions on specific matters, healthcare staff have a duty to make these decisions on the individual's behalf and in the individual's best interests. Preventing a non-autonomous person from killing themselves would be part of this process.

Beauchamp, in common with Dworkin, views paternalism as involving 'practices that restrict the autonomy of individuals without their consent to prevent some harm they will do to themselves or to produce some benefit they would not otherwise secure' (Beauchamp 1993: pp. 98-99). There are other views of paternalism, however. Battin (1996: p. 138) differentiates between autonomous and nonautonomous states. She calls the paternalism applied to non-autonomous individuals 'soft paternalism' and that applied to autonomous individuals 'hard paternalism' (the latter is similar to the paternalism described by Dworkin above).
Among the justifications for paternalistic suicide intervention, Cosculluela (1995) lists those highlighted at the beginning of this section: the evidence of a link between suicide and mental illness, the cry for help model, and considerations of ambivalence. If the reasons for an individual's ambivalence towards death can be explored with them and they can be given both practical help with their problems and psychological help in strengthening the aspect of their psyche that wants to survive, then the fact that they do not kill themselves and they have the chance to live a productive, happy life justifies paternalistic intervention.

Criticism of the above justifications is that it is not known with certainty what proportion of suicidal patients fit into each category. If only a small proportion of cases are cries for help or ambivalent, then paternalistic prevention strategies might impose needless and unjust interventions on rational individuals seeking suicide. However, given the finality of the outcome, doing all that can be done to help the person is, in our opinion, justifiable, even if the help involves depriving an acutely suicidal person of their liberty for a relatively short period.

\section{Objections to paternalistic prevention}

Battin (1996) discusses potential objections to paternalistic intervention, including its fallibility, for example in unnecessarily interfering with the liberty of a person attempting suicide that, by the nature of the attempt, would not have resulted in their death. She also raises the matter of the problems faced in trying to ascertain, in any given case, whether the criteria for paternalistic intervention have been met. She gives the example (p. 141) of a young woman found unconscious with an empty medicine bottle next to her: is the young woman's desire for suicide irrational or rational? The attempt might have been made with rational motives, for example the woman may be suffering from a terminal illness and have no dependants, family or debts.

Turning to Battin's first point, on fallibility, people who are genuinely suicidal may fail in their first attempt because of ignorance about the method they choose; if there is no intervention, they may be successful on their second attempt. Regarding her second criticism, to deny the unconscious woman intervention measures could be argued at best to be a callous unconcern for her welfare. In the UK, because of her unconscious state she would be treated in her best interests under incapacity legislation. ${ }^{\ddagger}$

Battin's argument about the difficulty of ascertaining the precise nature of a case before acting paternalistically raises the important point of whether a person's motives and intentions should
'For a related discussion in

Advances, see Biswas AB, Hiremath A (2010) Mental capacity assessment and 'best interests' decision-making in clinical practice: a case illustration. 16: 440-447. 
MCO answers

$\begin{array}{lllll}1 b & 2 c & 3 c & 4 b & 5 d\end{array}$ be determined in all cases before paternalistic intervention. As discussed above, it is reasonable to assume that most people who attempt suicide are mentally ill, ambivalent, making a cry for help, or a combination of all three. In the case of the unconscious woman in Battin's example, given the choice between causing potential harm by leaving her to die in case her attempt was rationally motivated, or acting paternalistically to prevent her dying and then discovering that she was perfectly rational in her attempt, the former is clearly the less morally acceptable. Not acting paternalistically would result in a preventable death. It may be regrettable to thwart the suicide attempts of the (likely) minority who are genuinely rational, autonomous and non-ambivalent, but the alternative, allowing people to kill themselves who might have gone on to lead happy, productive lives, is surely worse. The fictitious case in Box 2 illustrates potentially justified repeated paternalistic intervention.

\section{Shallow and deep autonomy}

In a consideration of the debate regarding physicianassisted suicide, Sneddon (2006) differentiates between 'shallow' and 'deep' autonomy. Shallow autonomy involves choices and decisions rooted in what the individual considers to be valuable. Deep autonomy involves the individual's capacity to reflect on these values and their worth.

This dichotomous view of autonomy is taken up by Nys (2008) in an article that takes a public health perspective on paternalism. Nys justifies paternalistic policies such as suicide prevention at the population level, since their aim is to prevent or aim to prevent a large amount of harm. He writes that deep autonomy in this context 'hinge[s] on a connection between health and the ability to reflect and reconsider one's values' (Nys 2008). This account is consistent with the view that to fail to

BOX 2 Is repeated brief paternalistic intervention justified?

A woman attempted suicide by taking an overdose after a relationship ended. She was detained by the police as she was behaving strangely in public following the overdose. At the initial mental health assessment she was helped with her housing and financial problems and discharged from police custody with only out-patient follow-up. Some time later, she attempts suicide again, this time by sitting on a bridge, intending to jump. It seems wrong to allow her to take her life and, given the short-term benefit of the previous intervention, it could be argued that further paternalistic intervention would be justified. respect a person's health in such a basic way as to allow harm such as suicide is to fail to respect their autonomy. Thus, deep autonomy provides further justification for paternalistic suicide prevention measures: while recognising the right of an autonomous person to want to take their own life, paternalistic intervention in a suicide attempt could be argued to allow them to be able to reflect on and reconsider this. It seems that an appeal to deep autonomy would justify short-term suicide prevention measures (over days or weeks).

\section{Longer-term suicide prevention measures}

Longer-term suicide prevention measures are generally criticised in the literature, particularly in the case of autonomous individuals (Beauchamp 1993; Battin 1996). In the vast majority of cases, prolonged detention of an autonomous individual in a psychiatric hospital with the sole aim of preventing their suicide would be an unjustifiable abuse of civil liberty. As discussed in the pages of this journal, Article 3 of the Human Rights Act 1998 protects against torture, inhuman or degrading treatment (Curtice 2008). Prolonged detention of autonomous individuals for the sole purpose of preventing suicide could be construed as inhuman if it causes the patient 'intense ... mental suffering' (Curtice 2008).

One might envisage a small number of cases in which patients might be detained for prolonged periods to prevent their suicide. These cases would involve people with severe mental illness who, following a period of detention under the Mental Health Act, recover to the extent that they regain their decision-making capacity regarding suicide. It could be argued to be ethically justifiable to continue the detention because of a duty to others. However, in these cases indefinite detention would be widely accepted as morally indefensible.

\section{Conclusions}

Short-term paternalistic interventions with the purpose of assessing a suicidal person for mental illness, treating such illness if it is found, counselling them, providing assistance with any problems they have and giving them time to reflect on their life and suicidal thoughts in a supportive environment is, in our opinion, ethically justifiable. Factors supporting this conclusion include the principle of respect for life, the evidence of mental illness in a significant proportion of suicide victims, the cry for help model, ambivalence in suicidal individuals and the individual's duty to others. Paternalistic intervention with autonomous individuals can also be justified using these factors, in addition to an appeal to preserve the individual's deep autonomy. 
Long-term paternalistic intervention with autonomous patients is usually morally impermissible on the grounds that it unjustifiably deprives them of their liberty.

\section{References}

Alvarez A (1980) The background. In Suicide: The Philosophical Issues (eds MP Battin, D Mayo). St Martin's Press.

Appelby J, Shaw J, Sherratt J, et al (2001) Safety First: Five-Year Report of the National Confidential Inquiry into Suicide and Homicide by People with Mental IIIness. Department of Health.

Baelz PR (1980) Suicide: some theological reflections. In Suicide: The Philosophical Issues (eds MP Battin, D Mayo). St Martin's Press.

Barraclough B, Bunch J, Nelson B, Sainsbury P (1974) A hundred cases of suicide: clinical aspects. British Journal of Psychiatry 125: $355-73$.

Battin MP (1996) The Death Debate: Ethical Issues in Suicide (pp 13758). Prentice Hall.

Beauchamp T (1993) Suicide. In Matters of Life and Death: New Introductory Essays in Moral Philosophy (eds T Regan, TL Beauchamp, JB Callicott, et al): 83-104. McGraw Hill.

Biggar N (2004) Aiming to Kill: The Ethics of Suicide and Euthanasia. Darton, Longman and Todd.

Brandt R (1980) The rationality of suicide. In Suicide: The Philosophical Issues (eds MP Battin, D Mayo). St Martin's Press.

Camus A (1942) Le Mythe de Sisyphe. Reprinted (1975) The Myth of Sisyphus (trans J O'Brien). Penguin.

Cavanagh JT, Carson AJ, Sharpe M, et al (2003) Psychological autopsy studies of suicide: a systematic review. Psychological Medicine 33: 395-405.

Cosculluela V (1995) The Ethics of Suicide. Garland Publishing.

Curtice M (2008) Article 3 of the Human Rights Act 1998: implications for clinical practice. Advances in Psychiatric Treatment 14: 389-97.

Department of Health (2002) National Suicide Prevention Strategy for England. Department of Health.
Durkheim E (1897) Suicide. Reprinted (2005) in Suicide: A Study in Sociology (trans JE Spalding, G Simpson): 175-200. Routledge.

Dworkin G (1972) Paternalism. The Monist 1: 64-84.

Glover J (1990) Causing Death and Saving Lives (pp 170-81). Penguin.

Hawton KS, Simkin S, Deeks JJ, et al (1999) Effects of a drug overdose in a television drama on presentations to hospital for self poisoning: time series and questionnaire study. BMJ 318: 972-7.

Hume D (c 1755) On Suicide. Reprinted (1965) in Of the Standard of Taste and Other Essays (ed J Lenz). Bobbs-Merril.

Jobes DA, Berman PW, O'Carroll PW, et al (1996) The Kurt Cobain suicide crisis: perspectives from research, public health, and the news media. Suicide and Life Threatening Behaviour 26: 260-71.

Kessler RC, McGonagle KA, Zhao S, et al (1994) Lifetime and 12 month prevalence of DSM-III-R psychiatric disorders in the United States: results from the National Comorbidity Survey. Archives of General Psychiatry 51: 8-19.

Mill JS (1859) On Liberty. Reprinted (1961) in Essential Works of John Stuart Mill. Bantam.

NUJ Scotland (2007) The Reporting of Mental Health and Suicide by the Media: A Practical Guide for Journalists. National Union of Journalists (http://www.iasp.info/pdf/task_forces/Scotland_Reporting_Media.pdf). Nys TRV (2008) Paternalism in public health care. Public Health Ethics 1: $64-72$.

0'Connor C (2009) Jan Palach - the student whose self-immolation still haunts Czechs today. Radio Praha (http://www.radio.cz/en/ article/112440)

Pirkis J (2009) Suicide and the media. Psychiatry 8: 269-71

Schmidtke A, Häfner $H$ (1989) Public attitudes towards and effects of the mass media on suicidal and deliberate self-harm behaviour. In Suicide and its Prevention: The Role of Attitude and Imitation (eds R Diekstra, R Maris, S Platt, et al): 313-30. E. J. Brill.

Sneddon A (2006) Equality, justice and paternalism: re-centering debate about physician assisted suicide. Journal of Applied Philosophy 23: 387-404

Stack S (1991) Social correlates of suicide by age: media impacts. In Life Span Perspectives of Suicide: Time-Lines in the Suicide Process (ed AA Leenaars): 187-213. Plenum Press.
MCOs

Select the single best option for each question stem

1 On historical perspectives:

a Aquinas taught that suicide is morally permissible

b Augustine wrote that suicide is an offence against God

c suicide was illegal in the UK until 1983

d people who unsuccessfully attempted suicide were executed in Britain as late as 1961

e Kant wrote that suicide when chosen autonomously is morally permissible.

\section{David Hume wrote that:}

a suicide is impermissible because of the individual's duty to others

b suicide prevention is justified by an appeal to deep autonomy

c suicide can be an honourable act

$\mathrm{d}$ members of the public are morally justified in reporting suicide threats

e suicide is sometimes permissible when an individual is rational.
3 Perspectives on suicide intervention:

a the 2001 National Confidential Inquiry in the UK showed that alcohol dependence is the most common diagnosis in patients who die by suicide and who were in contact with mental health services in the year before death

b the ambivalence model provides evidence against short-term suicide prevention

c Barraclough found that in over $90 \%$ of a sample of suicide cases, the individuals were diagnosable with a mental disorder

$d$ the cry for help model involves individuals genuinely wishing to die

e members of the public are never morally justified in reporting suicide threats.

4 J. S. Mill believed that:

a suicide prevention is never justified

$\mathrm{b}$ individuals are justified in temporarily intervening in suicide attempts

c suicide by individuals with terminal illness is sometimes justified $d$ the principle of respect for life means that suicide is never morally justified

e prolonged paternalistic suicide intervention is morally justifiable in most cases.

5 Regarding paternalism:

a an appeal to deep autonomy denies paternalistic suicide intervention

b short-term paternalistic suicide prevention measures are widely considered to be morally impermissible

c the cry for help model of suicide means that paternalistic interventions are not morally justifiable

d Beauchamp views paternalism as applying only to autonomous individuals

e long-term paternalistic suicide prevention with autonomous individuals is considered morally impermissible. 